\title{
Oridonin induces the apoptosis of mucoepidermoid carcinoma cell lines in a myeloid cell leukemia-1-dependent manner
}

\author{
JUNG-MIN HAN $^{1 *}$, KYOUNG-OK HONG $^{1 *}$, IN-HYOUNG YANG ${ }^{2}$, CHI-HYUN AHN ${ }^{1}$, BOHWAN JIN $^{3}$, \\ WONWOO LEE ${ }^{3}$, YUN CHAN JUNG ${ }^{4}$, KYUNG-A KIM ${ }^{5}$, JI-AE SHIN ${ }^{1}$, SUNG-DAE CHO ${ }^{1}$ and SEONG-DOO HONG ${ }^{1}$ \\ ${ }^{1}$ Department of Oral Pathology, School of Dentistry and Dental Research Institute, \\ Seoul National University, Seoul 03080, Republic of Korea; ${ }^{2}$ Cancer Center, School of Medicine, \\ Texas Tech University Health Sciences Center, Lubbock, TX 79430, USA; ${ }^{3}$ Laboratory Animal Center, \\ CHA University, CHA Biocomplex, Seongnam, Gyeonggi 13488; ${ }^{4}$ Chaon, Seongnam, Gyeonggi 13488; \\ ${ }^{5}$ Department of Dentistry, School of Medicine, Eulji University, Daejeon 34824, Republic of Korea
}

Received December 10, 2019; Accepted April 24, 2020

DOI: 10.3892/ijo.2020.5061

\begin{abstract}
Oridonin, an active diterpenoid isolated from Rabdosia rubescens, has been reported to exhibit anticancer activities in several tumors. The aim of the present study was to investigate the anticancer effects and molecular mechanisms of oridonin in mucoepidermoid carcinoma (MEC). Treatment with oridonin induced the apoptosis of MC-3 and YD-15 cell and inhibited the expression of myeloid cell leukemia-1 (MCL-1) through the regulation of the protein level through post-translational regulation in these cell lines. Oridonin significantly increased the expression level of truncated Bid (t-Bid) as a downstream target of MCL-1 and subsequently decreased the mitochondrial membrane potential. The ectopic expression of MCL-1 protein was sufficient to reverse the induction of apoptosis and the increased t-Bid expression induced by oridonin in both cell lines. Taken together, these results suggest that oridonin exerts an apoptotic effect through the modulation of MCL-1 and t-Bid in human MEC cell lines and may thus be a potential anticancer drug candidate for the treatment of human MEC.
\end{abstract}

Correspondence to: Professor Sung-Dae Cho or Professor Seong-Doo Hong, Department of Oral Pathology, School of Dentistry and Dental Research Institute, Seoul National University, Seoul 03080, Republic of Korea

E-mail: efiwdsc@snu.ac.kr

E-mail: hongsd@snu.ac.kr

*Contributed equally

Abbreviations: MEC, mucoepidermoid carcinoma; t-Bid, truncated Bid; MCL-1, myeloid cell leukemia-1; PARP, poly (ADP-ribose) polymerase; MOMP, mitochondrial outer membrane permeabilization

Key words: mucoepidermoid carcinoma, oridonin, apoptosis, myeloid cell leukemia-1, truncated-Bid

\section{Introduction}

Mucoepidermoid carcinoma (MEC) is the most common malignant tumor of the salivary gland, and is well known for having a considerable cellular heterogeneity, including epidermoid, intermediate and mucin-producing cells $(1,2)$. Patients with high-grade and advanced stages of the disease have been reported to be exhibit poor survival rates (3). Although radiotherapy and chemotherapy with surgery are the main treatment modalities for MEC (4,5), various side-effects associated with these treatments have been reported (6). To overcome these limitations, it is important to continue to identify novel tumor-specific molecular target and explore new, efficient and less toxic drug candidates for the treatment of MEC.

B-cell lymphoma 2 (Bcl-2) family member is highly conserved across species and is known to be a promising target for chemotherapy (7). Myeloid cell leukemia-1 (MCL-1), an anti-apoptotic member of the Bcl-2 family, has been shown to play an anti-apoptotic role in cell survival $(8,9)$. MCL-1 is also overexpressed and is associated with poor outcomes of various malignant tumors, including hepatocellular carcinoma (10), breast cancer (11) and esophageal squamous cell carcinoma (12). It sequesters pro-apoptotic members of the Bcl-2 family, such as Bax, Bak, Bim and t-Bid through its direct binding to them, followed by blocking their oligomerization for the formation of protein-permeable pores on the mitochondrial outer membrane $(13,14)$. Finally, a decrease in MCL-1 expression allows for the release of cytochrome $c$ into the cytoplasm, leading to the activation of the caspase cascade and ultimately, to the induction of apoptosis $(15,16)$. It is therefore important to consider MCL-1 as a chemotherapeutic target for a variety of cancer types.

Oridonin is a diterpenoid extracted from the medicinal herb, Rabdosia rubescens, which has attracted much research interest as it exhibits anticancer effects in various cancer cells $(17,18)$. The anticancer mechanisms of oridonin include the Fas/FasL-mediated extrinsic apoptotic pathway, phosphoinositide 3-kinase (PI3K)/Akt or mitogen-activated protein kinase (MAPK) signaling pathway-related intrinsic apoptotic pathway (19-22). In addition, recent studies have demonstrated 
that oridonin exerts mitochondria-mediated apoptotic effects on a variety of cancer cells through the Bcl-2 family $(23,24)$. However, the precise effects of oridonin on MEC cells and the underlying mechanism have not been studied yet.

In the present study, the anticancer effects of oridonin and the apparent underlying mechanisms were investigated in MC-3 and YD-15 human MEC cell lines.

\section{Materials and methods}

Cell culture and chemical treatment. MC-3 and YD-15 cell lines were obtained from the Fourth Military Medical University and Yonsei University, respectively. Both cell lines were maintained in either DMEM/F12 or RPMI-1640 medium (Welgene, Inc.) supplemented with $10 \%$ fetal bovine serum (Welgene, Inc.) and $100 \mathrm{U} / \mathrm{ml}$ each penicillin (Welgene, Inc.) in a humidified atmosphere containing $5 \% \mathrm{CO}_{2}$ at $37^{\circ} \mathrm{C}$. During the culture process, the cells were routinely investigated under a microscope (CKX53, Olympus Corp.) for fungal and mycoplasma contamination and the mycoplasma removal agent (MP Biomedicals, LLC) was used to treat the mycoplasma-free cultures if deemed necessary. All experiments were performed with cells cultured at 50-60\% confluency. Oridonin (chemical structure shown in Fig. 1A) was purchased from Abcam and cycloheximide (CHX) were obtained from Sigma-Aldrich; Merck KGaA. Each chemical was dissolved in dimethyl sulfoxide (DMSO), aliquoted and stored at $-20^{\circ} \mathrm{C}$. Stock solutions were diluted with culture medium to the indicated concentrations (final DMSO concentration, $0.1 \%$ ).

Trypan blue exclusion assay. The effects of oridonin on cell viability were investigated using Trypan blue exclusion assay. Cells were incubated with the vehicle control (0.1\% DMSO) or oridonin for $48 \mathrm{~h}$ at $37^{\circ} \mathrm{C}$, stained with $0.4 \%$ trypan blue solution (Gibco; Thermo Fisher Scientific, Inc.) for 2 min at room temperature, and viable cells were counted using a hemocytometer (Marienfeld).

Live/dead assay. The Live/Dead and Viability/Cytotoxicity assay kit (Invitrogen; Thermo Fisher Scientific, Inc.) was used to determine the cytotoxicity of oridonin in the MEC cell lines. Calcein-AM is retained in living cells, producing intense green fluorescence through intracellular esterase activity. Ethidium homodimer-1 enters dead cells with damaged membranes and binds to nucleic acids, producing bright red fluorescence. Briefly, cells were stained with $2 \mu \mathrm{M}$ calcein-AM and $4 \mu \mathrm{M}$ ethidium homodimer-1 and incubated for $30 \mathrm{~min}$ at room temperature. Cells were analyzed under a fluorescence microscope (Leica DM5000B; Leica Microsystems GmbH) with a suitable excitation and emission filter.

Western blot analysis. Whole-cell lysates were extracted with RIPA lysis buffer (EMD Millipore) containing phosphatase inhibitors (Thermo Fisher Scientific) and protease inhibitor cocktails (Roche Diagnostics GmbH). Protein concentrations were measured using a DC protein assay kit (Bio-Rad Laboratories, Inc.). Proteins at the same concentration $(20 \mu \mathrm{g})$ were separated by SDS-polyacrylamide gel electrophoresis in $12 \%$ acrylamide gel (Bio-Rad Laboratories, Inc.) and electrotransferred to a polyvinylidene fluoride membrane (Pall Corporation). The membranes were blocked with 5\% skim milk dissolved in Tris-buffered saline-Tween-20 buffer (T-BST) for $1 \mathrm{~h}$ at room temperature. The membranes were then washed with T-BST and incubated with primary antibodies overnight at $4^{\circ} \mathrm{C}$. Subsequently, the membranes were incubated with horseradish peroxidase-conjugated secondary antibodies at room temperature for $2 \mathrm{~h}$. Rabbit anti-human polyclonal antibodies against cleaved caspase-3 (cat. no. 9664; 1:1,000), cleaved poly (ADP-ribose) polymerase (PARP; cat. no. 9541; 1:1,000), Bcl-xL (cat. no. 2764; 1:1,000), Bak (cat. no. 3814; 1:1,000), Bax (cat. no. 2772; 1:1,000), Bim (cat. no. 2819; 1:1,000) and MCL-1 (cat. no. 4572; 1:1,000) were obtained from Cell Signaling Technology, Inc. Mouse anti-human monoclonal antibodies against active-Bak (cat. no. AM04; 1:1,000) was purchased from EMD Millipore. Mouse anti-human monoclonal antibodies against active-Bax (cat. no. 556467; 1:1,000) was obtained from BD Biosciences. Goat anti-human polyclonal antibodies against t-Bid (cat. no. 34325; 1:1,000) and mouse anti-human monoclonal antibodies against $\beta$-actin (cat. no. sc47778; 1:3,000) were purchased from Santa Cruz Biotechnology, Inc. Antibody-bound proteins were detected using enhanced chemiluminescence Western blotting Luminol reagent (Santa Cruz Biotechnology, Inc.) and visualized using a LAS-500 imaging system (GE Healthcare Life Sciences). The densitometric analysis of the western blots was performed using ImageJ software (version $1.51 \mathrm{k}, \mathrm{NIH}$ ).

Flow cytometric analysis. Flow cytometry was performed to analyze the cell cycle and apoptosis of the MEC cell lines. Cells were harvested after being treated with various concentrations of oridonin $(0-30 \mu \mathrm{M})$ for $48 \mathrm{~h}$, washed twice with PBS, and fixed with $70 \%$ ethanol at $-20^{\circ} \mathrm{C}$ for overnight. Cells were then re-suspended in PBS containing $20 \mu \mathrm{g} / \mathrm{ml}$ RNase $A$ and propidium iodide (P4170, Sigma-Aldrich; Merck $\mathrm{KGaA}$ ) for $15 \mathrm{~min}$ at $37^{\circ} \mathrm{C}$. DNA contents were detected using a fluorescence-activated cell sorter (FACS) Calibur (BD Biosciences) and relative DNA content was calculated with Cell Quest software (BD Biosciences).

4'-6-Diamidino-2-phenylindole (DAPI) staining. DAPI solution (Sigma-Aldrich; Merck KGaA) was used to investigate the nuclear morphological changes of apoptotic cells. Cells seeded on $60 \mathrm{~mm}^{2}$ plates were treated with various concentrations of oridonin $(0-30 \mu \mathrm{M})$ for $48 \mathrm{~h}$. Following treatment, the cells were harvested, washed twice with PBS, and fixed with $100 \%$ methanol at room temperature for $10 \mathrm{~min}$. The cells were washed again with PBS, plated on coated glass slides, and stained with $2 \mu \mathrm{g} / \mathrm{ml}$ of DAPI solution for $1 \mathrm{~min}$ at room temperature. The morphological changes of the cells were observed under a fluorescence microscope (Leica DM5000B, Leica Microsystems $\mathrm{GmbH}$ ).

Annexin V/propidium iodide (PI) staining. Apoptosis was measured using a FITC Annexin V apoptosis detection kit (BD Pharmingen). Harvested cells were washed twice with PBS and stained with Annexin V-FITC and PI dye at room temperature for $15 \mathrm{~min}$. The stained cells were then analyzed using a FACSCalibur flow cytometer and calculated using Cell Quest software (BD Biosciences). 
A

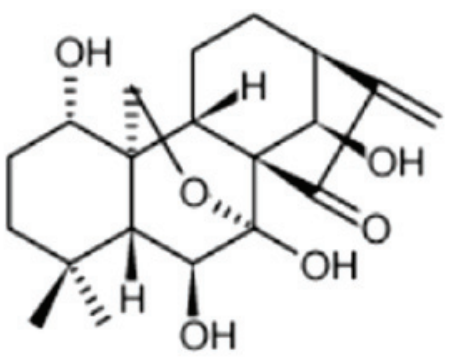

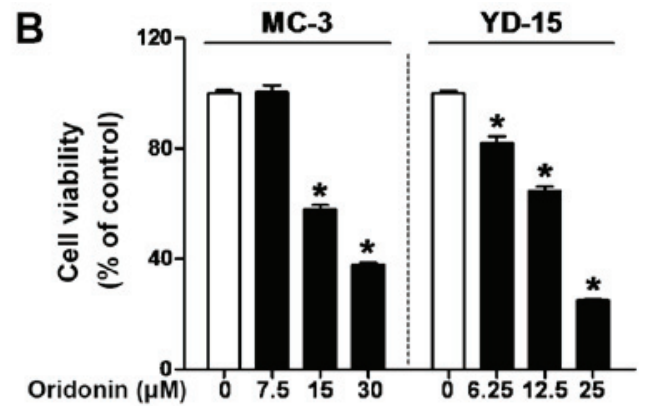

C

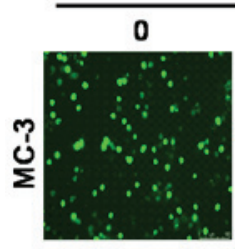

0

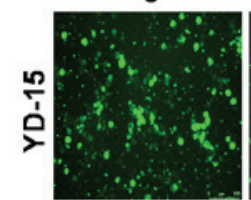

Oridonin $(\mu \mathrm{M})$

7.5

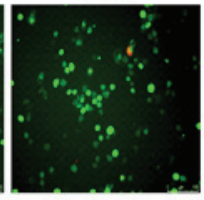

6.25

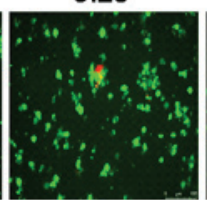

\section{5}

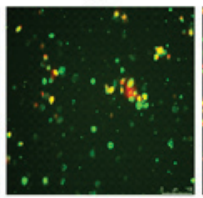

12.5

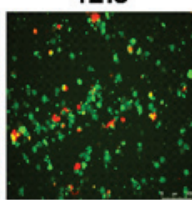

30

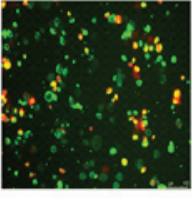

25

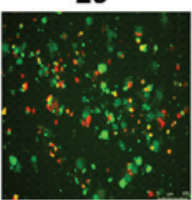

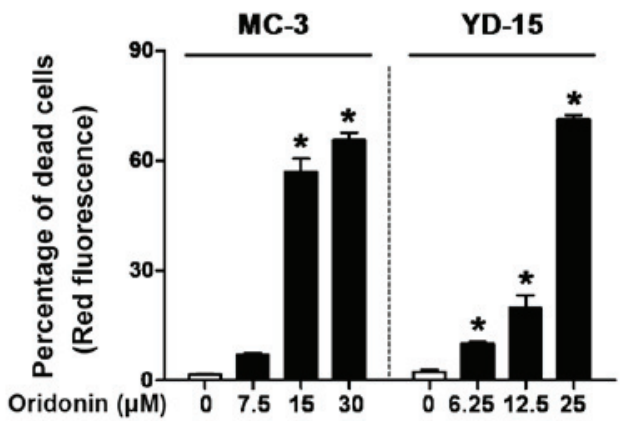

Figure 1. Effects of oridonin on the viability of MEC cell lines. (A) Chemical structure of oridonin. (B) MC-3 and YD-15 cells were treated with DMSO or oridonin $(0$ to $30 \mu \mathrm{M})$ for $48 \mathrm{~h}$ and cell viability was determined using a Trypan blue exclusion assay. (C) Cytotoxic effect of oridonin was estimated using a Live/Dead assay. The percentage of dead cells was quantified. Graph shows the means \pm SD of 3 independent experiments. "P $<0.05$, significant difference compared with the control group. MEC, mucoepidermoid carcinoma.

Reverse transcription and polymerase chain reaction (RT-PCR) and semi-quantitative PCR. Total RNA was isolated using the Easy-BLUE total RNA extraction kit (iNtRON Biotechnology) and cDNA was synthesized using a cDNA synthesis kit (Enzo Life Sciences, Inc.). The resulting target cDNA was subjected to PCR using HiPi PCR PreMix (ELPISBIOTECH, Inc.) and amplified using the following primers: MCL-1 sense, 5'-GAGGAGGAGGACGAGTTG TA-3' and antisense 5'-CCTTACGAGAACGTCTGTTGT GATAC-3'; and GAPDH sense, 5'-CGGAGTCAACGGATT TGGTCGTAT-3' and antisense, 5'-AGCCTTCTCCATGGT GGTGAAGAC-3'. The amplification of MCL-1 and GAPDH was performed for 28 cycles $\left(30 \mathrm{sec}\right.$ at $95^{\circ} \mathrm{C}, 35 \mathrm{sec}$ at $60^{\circ} \mathrm{C}$ and $45 \mathrm{sec}$ at $72^{\circ} \mathrm{C}$ ). The amplified PCR products were detected using $2 \%$ agarose gel electrophoresis and visualized by ethidium bromide staining. The densitometric analysis of the amplified PCR products was performed using ImageJ software (version $1.51 \mathrm{k}, \mathrm{NIH}$ ).

Quantitative (real-time) PCR ( $q P C R)$. The resulting target cDNA was subjected to PCR using AMPIGENE qPCR Green Mix Hi-Rox (Enzo Life Sciences, Inc). qPCR was performed by a StepOne Plus Real-Time PCR System (Applied Biosystems) and the resulting target cDNA was amplified using the following primers: MCL-1 sense, 5'-GTATCACAG ACGTTCTCGTAAGG-3' and antisense, 5'-CCACCTTCT AGGTCCTCTACAT-3'; and GAPDH sense, 5'-GTGGTCTCC TCTGACTTCAAC-3' and antisense, 5'-CCTGTTGCTGTA GCCAAATTC-3'. The amplification of MCL-1 and GAPDH was performed for 40 cycles $\left(2 \mathrm{~min}\right.$ at $95^{\circ} \mathrm{C} 10 \mathrm{sec}$ at $95^{\circ} \mathrm{C}$ and
$30 \mathrm{sec}$ at $\left.60^{\circ} \mathrm{C}\right)$. Each PCR product was run in triplicate. The relative MCL-1 mRNA expression was calculated using the $2^{-\Delta \Delta \mathrm{Cq}}$ method (25).

Cycloheximide (CHX) chase assay. Cycloheximide (Sigma-Aldrich; Merck KGaA) chase assay was carried out to examine whether oridonin affected the half-life of MCL-1 protein. In brief, the cells were treated with $0.05 \mu \mathrm{g} / \mathrm{ml}$ of CHX $1 \mathrm{~h}$ prior to oridonin treatment, and were subsequently treated with or without oridonin for the indicated periods of time (0-12 h). Western blot analysis was then performed.

Mitochondrial membrane potential $(\Delta \Psi m)$ assay. Changes in $\Delta \Psi \mathrm{m}$ were determined using a MitoScreen kit (BD Pharmingen). Harvested cells were washed twice with PBS and incubated with JC-1 solution at $37^{\circ} \mathrm{C}$ for $30 \mathrm{~min}$. The cells washed twice using 1X Assay Buffer and JC-1 fluorescence was analyzed by flow cytometry (FACSCalibur, BD Biosciences).

Construction of MCL-1 overexpression vector and transient transfection. The open reading frame of the human MCL-1 (NM_021960) gene was amplified from cDNA using the following primers: MCL-1 sense, 5'-GAATTCATGTTTGGC CTCAAAAGA-3', with an included EcoRI site; and MCL-1 antisense, 5'-GAATTCCTATCTTATTAGATATGC-3', with an included EcoRI site and cloned into a pGEM ${ }^{\circledR}-\mathrm{T}$ Easy Vector System (Promega Corporation). The genes were cloned into the multiple cloning site of pcDNA3.1(+) vector (Invitrogen; Thermo Fisher Scientific, Inc.). The MC-3 and YD-15 cells were transfected with the empty pcDNA3.1 
A

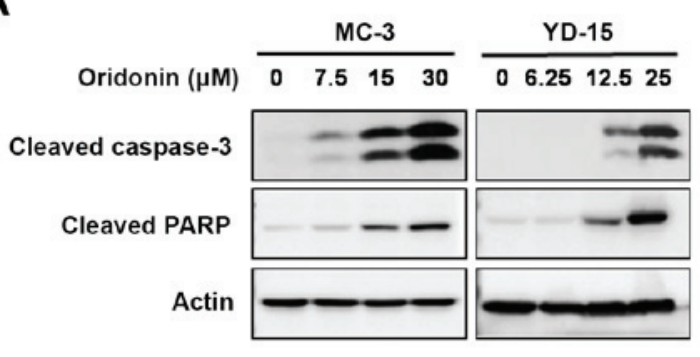

B

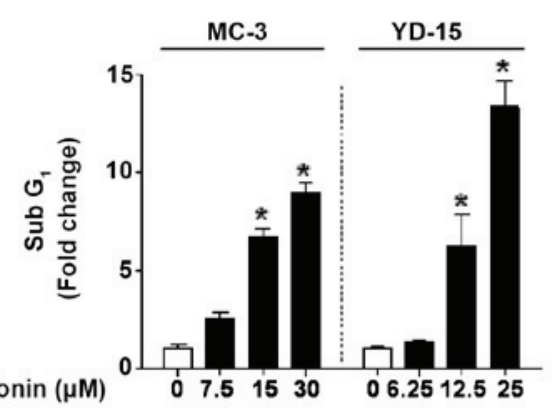

C
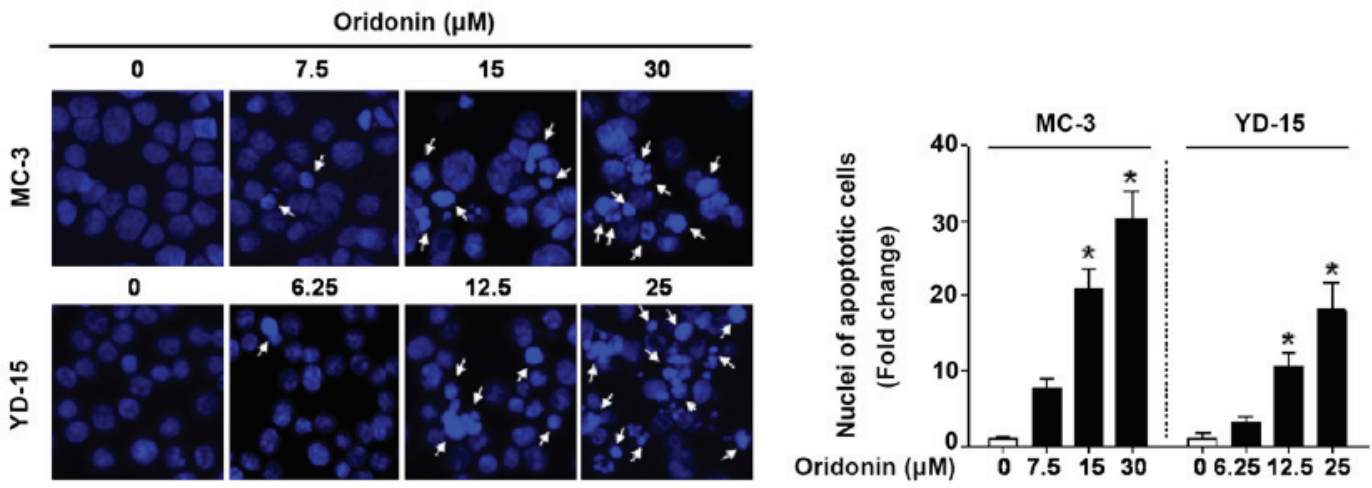

D
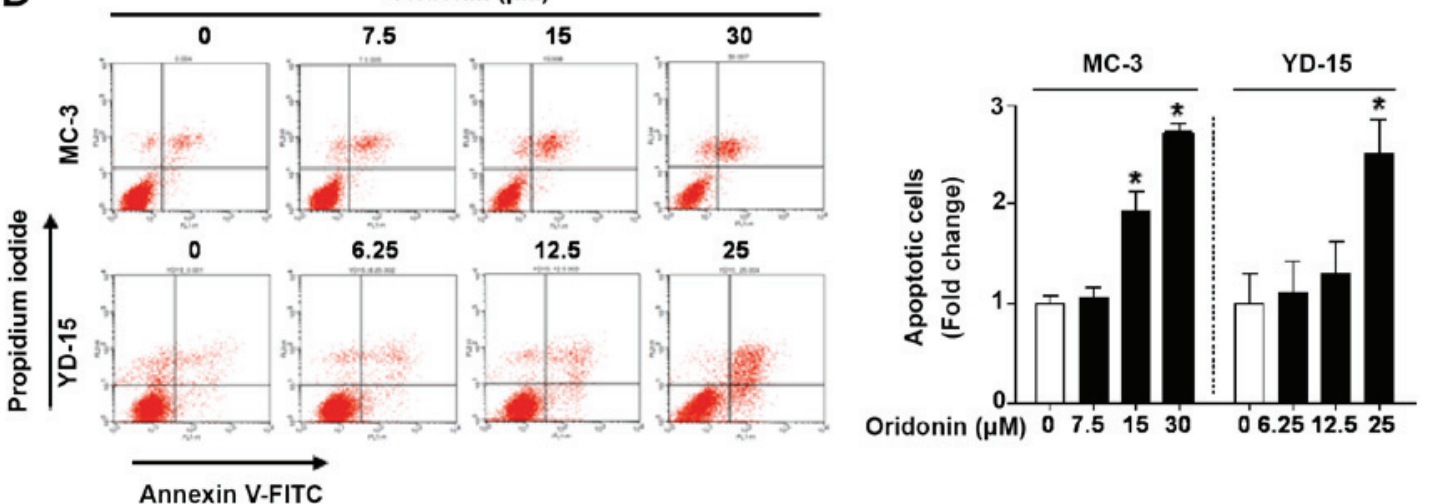

Figure 2. Effect of oridonin on the apoptosis of MEC cell lines. (A) The apoptotic effects of oridonin were determined by western blot analysis of the levels of cleaved caspase-3 and PARP. B-actin was used as the control for normalization. (B) The sub $\mathrm{G}_{1}$ cell population was analyzed by PI staining. (C) Apoptotic features, such as chromatin condensation and nuclear fragmentation were detected by DAPI staining (indicated by white arrows). (D) Annexin V/PI staining in MC-3 and YD-15 cells treated with DMSO or oridonin for $48 \mathrm{~h}$ was performed to detect apoptosis. Graph shows the means \pm SD of 3 independent experiments. ${ }^{*} \mathrm{P}<0.05$, significant difference compared with the control group. MEC, mucoepidermoid carcinoma; PARP, poly(ADP-ribose) polymerase.

or the pcDNA3.1- MCL-1 vector $(0.5 \mu \mathrm{g})$ construct using Lipofectamine 2000 reagent (Invitrogen; Thermo Fisher Scientific, Inc.) according to the manufacturer's instructions.

Statistical analysis. Statistical analysis was performed using SPSS 22 software (SPSS, Inc.). A one-way analysis of variance (ANOVA) was applied with Tukey's post hoc test and all data are presented as the means \pm standard deviation. $\mathrm{P}<0.05$ was considered to indicate a statistically significant difference.

\section{Results}

Oridonin inhibits the viability and induces the death of human MEC cell lines. To investigate the growth-inhibitory effects of oridonin, the MC-3 and YD-15 cells were incubated with various concentrations of oridonin (0-30 $\mu \mathrm{M})$ for $48 \mathrm{~h}$. The results revealed that statistical significance was observed at the 15 and $30 \mu \mathrm{M}$ concentrations of oridonin for the MC-3 cells and at the $6.25,12.5$ and $25 \mu \mathrm{M}$ concentrations for the YD-15 cells (Fig. 1B). To determine the cytotoxic effects of oridonin, a Live/Dead assay was performed under the same conditions as a Trypan blue exclusion assay in the MEC cell lines. As illustrated in Fig. 1C, treatment with oridonin led to an increase in the ratio of dead cells (red fluorescence) in a concentration-dependent manner. These results indicate that oridonin inhibits the viability and induces the death of MEC cell lines.

Oridonin induces the apoptosis of MEC cell lines. To determine the type of cell death induced by oridonin, the levels of PARP and caspase-3, as markers of apoptosis, were detected by western blot analysis. In response to oridonin treatment, the cleavage of caspase- 3 and PARP was markedly increased compared with the vehicle control (Fig. 2A). To examine 
A

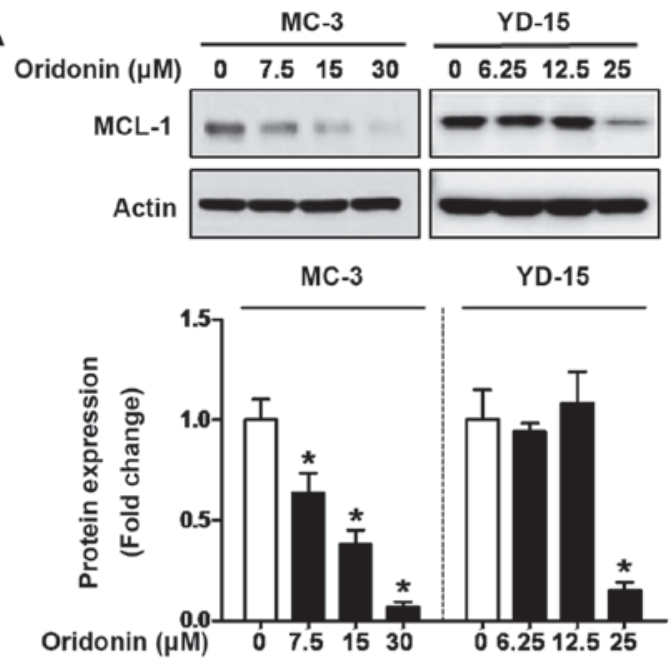

B

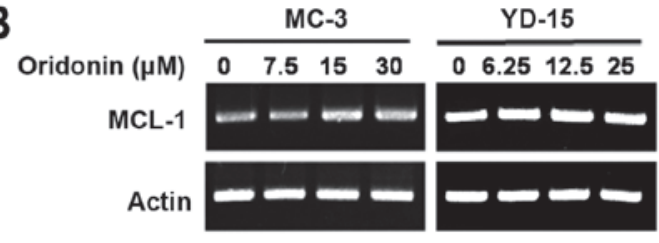

C

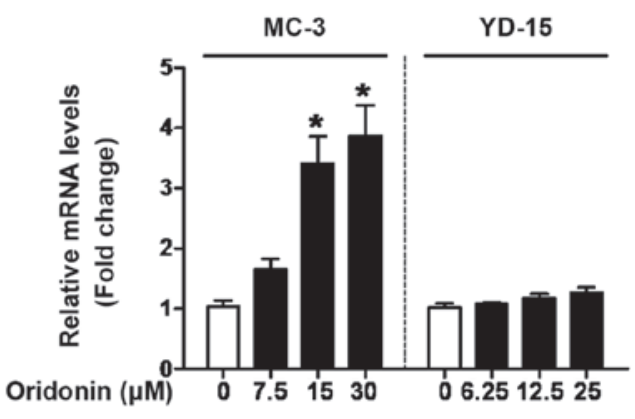

D

YD-15

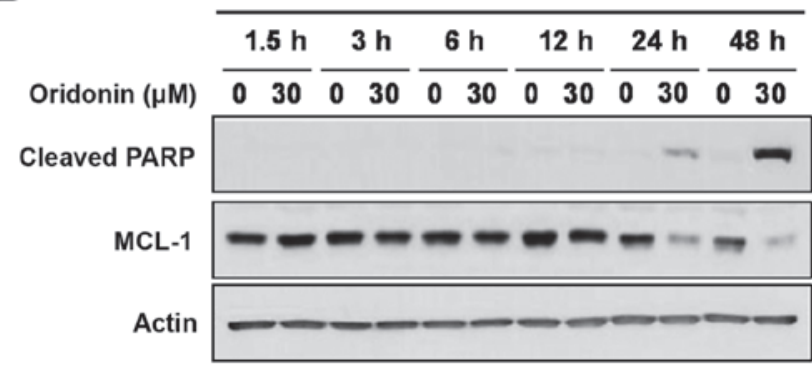

E
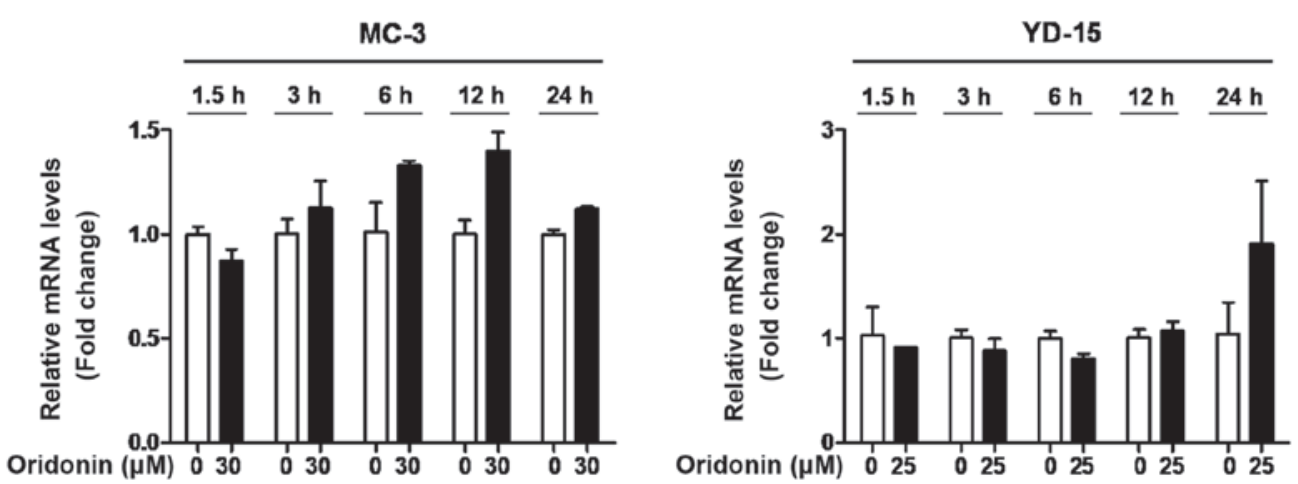

Figure 3. Inhibitory effects of oridonin on MCL-1 protein expression in MEC cell lines. (A) The effects of DMSO or oridonin for $48 \mathrm{~h}$ on MCL-1 protein were determined by western blot analysis. mRNA level of MCL-1 was detected by (B) RT-PCR and (C) qPCR. Expression levels of MCL-1 protein or mRNA were determined in a time-dependent manner by (D) western blot analysis and (E) qPCR, respectively. Graph shows the means \pm SD of 3 independent experiments. ${ }^{*} \mathrm{P}<0.05$, significant difference compared with the control group. MEC, mucoepidermoid carcinoma; PARP, poly(ADP-ribose) polymerase; MCL-1, myeloid cell leukemia-1.

the effects of oridonin on the sub $\mathrm{G}_{1}$ cell population, flow cytometry was performed. The cell population in the sub $\mathrm{G}_{1}$ phase increased from 8.96- to 13.31-fold in the MC-3 and YD-15 cell lines treated with oridonin (Fig. 2B). When visualizing cell apoptosis by DAPI staining, oridonin was found to significantly increase the number of apoptotic nuclei with condensation or fragmentation (white arrows) in the MEC cell lines (Fig. 2C). To further verify the apoptotic effects of oridonin, Annexin V/PI double staining was performed. The results revealed that the number of Annexin-positive cells was significantly increased in a concentration-dependent manner (Fig. 2D). Taken together, these results suggest that oridonin enhances the apoptotic death of human MEC cell lines.
Oridonin downregulates MCL-1 protein expression through post-translational modification. To elucidate the fundamental mechanisms of oridonin-induced apoptosis, the expression of Bcl-2 family was identified as a key mediator of apoptosis. The results of western blot analysis revealed that treatment with oridonin significantly decreased the expression level of MCL-1 protein and increased PARP cleavage in a concentration- and time-dependent manner (Fig. 3A and D); however, oridonin did not affect the expression of other anti-apoptotic proteins (e.g., Bcl-xL) in both cell lines (Fig. S1). To determine whether MCL-1 is regulated at the transcriptional level, RT-PCR and qPCR were performed. The effect of oridonin on MCL-1 mRNA levels was variable in both cell lines (Fig. 3B, C and E). 
A

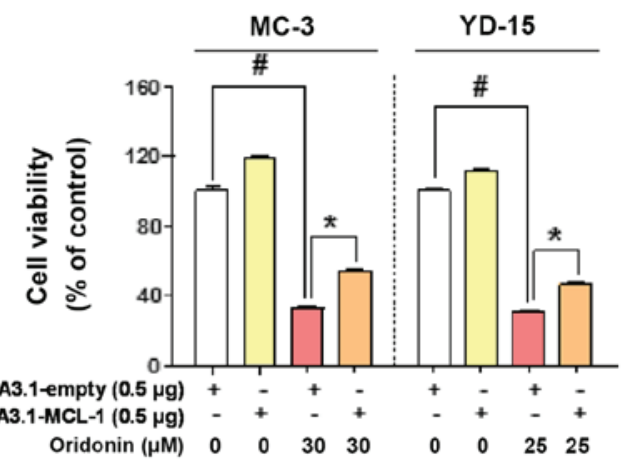

B
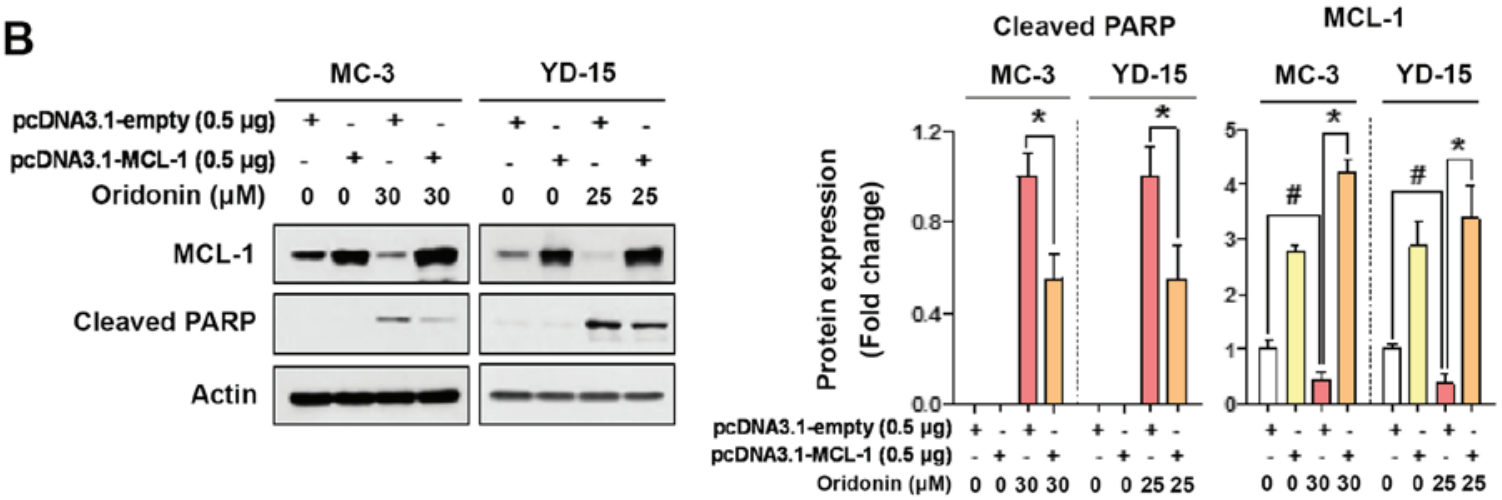

C
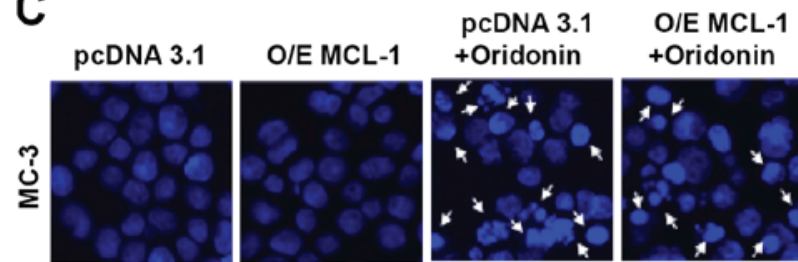

Oridonin $(\mu M) \quad 0 \quad 03030 \quad 0 \quad 02525$

$0 \begin{array}{lllllll}03030 & 0 & 0 & 2525\end{array}$
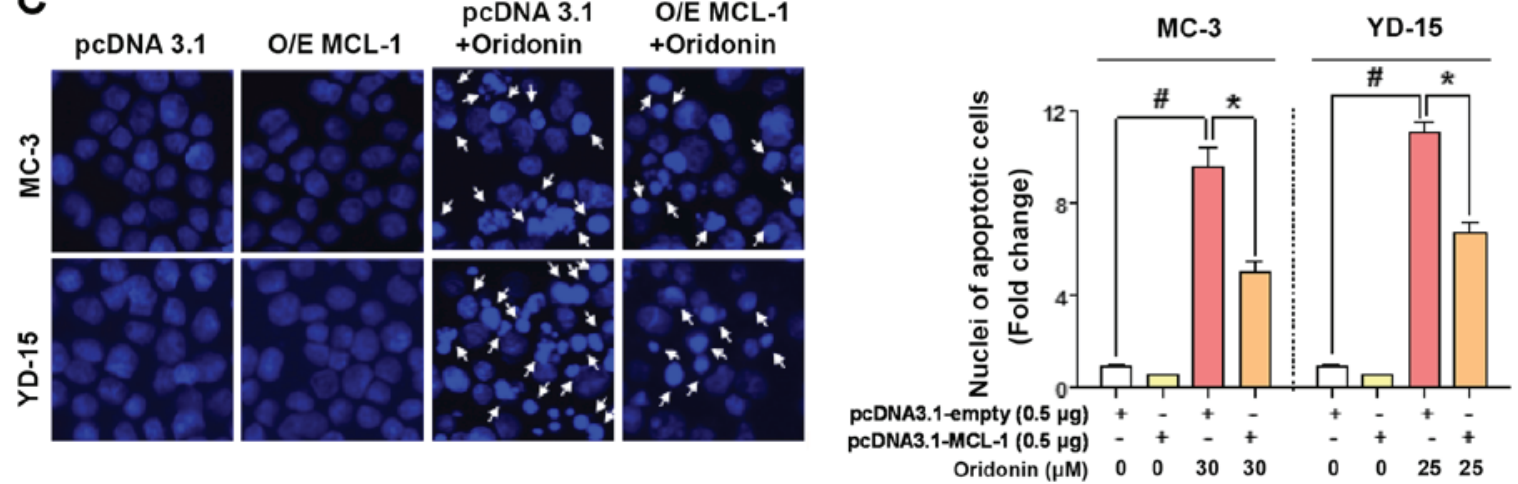

Figure 4. Apoptotic effect of oridonin through the depletion of MCL-1 protein in MEC cell lines. Cells were transiently transfected with $0.5 \mu \mathrm{g}$ of empty pcDNA3.1 or pcDNA3.1-MCL-1. After $6 \mathrm{~h}$, both cell lines were treated with oridonin for $48 \mathrm{~h}$. (A) Cell viability was determined by a Trypan blue exclusion assay. (B) Expression levels of MCL-1 and cleaved PARP were determined by western blot analysis. (C) Apoptotic features were detected by DAPI staining. Graph shows the means \pm SD of 3 independent experiments. " $\mathrm{P}<0.05$, significant difference compared with the empty pcDNA3.1 vector- group; ${ }^{*} \mathrm{P}<0.05$, significant difference compared with the oridonin treated-group. MEC, mucoepidermoid carcinoma; PARP, poly(ADP-ribose) polymerase; MCL-1, myeloid cell leukemia-1.

To further determine the effect of oridonin on MCL-1 protein turnover, chasing analysis was performed using cycloheximide (CHX), an inhibitor of protein synthesis, followed by western blot analysis. As a result, the MCL-1 protein levels were markedly decreased by simultaneous treatment with oridonin and CHX compared to CHX treatment only (Fig. S2, top panel). The half-life of MCL-1 protein in the cells treated with both oridonin and CHX was approximately 11.5 and $10.8 \mathrm{~h}$ compared with 23.3 and $44.0 \mathrm{~h}$ in the CHX-treated group in the MC-3 and YD-15 cells, respectively (Fig. S2 bottom panel). These results suggest that the mode of action of oridonin is through the inhibition of the MCL-1 protein level.

Depletion of MCL-1 protein is associated with the oridonin-induced apoptosis of MEC cell lines. To verify whether the effects of oridonin-mediated apoptosis are dependent on MCL-1, the two cell lines were transfected with an empty vector or a MCL-1 expression vector. MCL-1 overexpression significantly restored cell viability and PARP cleavage, which were previously affected by oridonin in both cell lines (Fig. 4A and B). This observation was further confirmed by the result that the ratio of apoptotic nuclei in MCL-1 overexpressing cells was reduced compared with the control (Fig. 4C). These results suggest that the principal mechanism of oridonin-mediated apoptosis may involve the targeting of MCL-1 protein in human MEC cell lines.

Oridonin induces mitochondrial apoptosis by regulating the $M C L-1 / t$-Bid signaling axis. The majority of apoptotic stimuli require mitochondrial outer membrane permeabilization (MOMP) by pro-apoptotic proteins, such as Bax, Bak, Bim and t-Bid (26). In the present study, JC-1 staining was performed to 
A
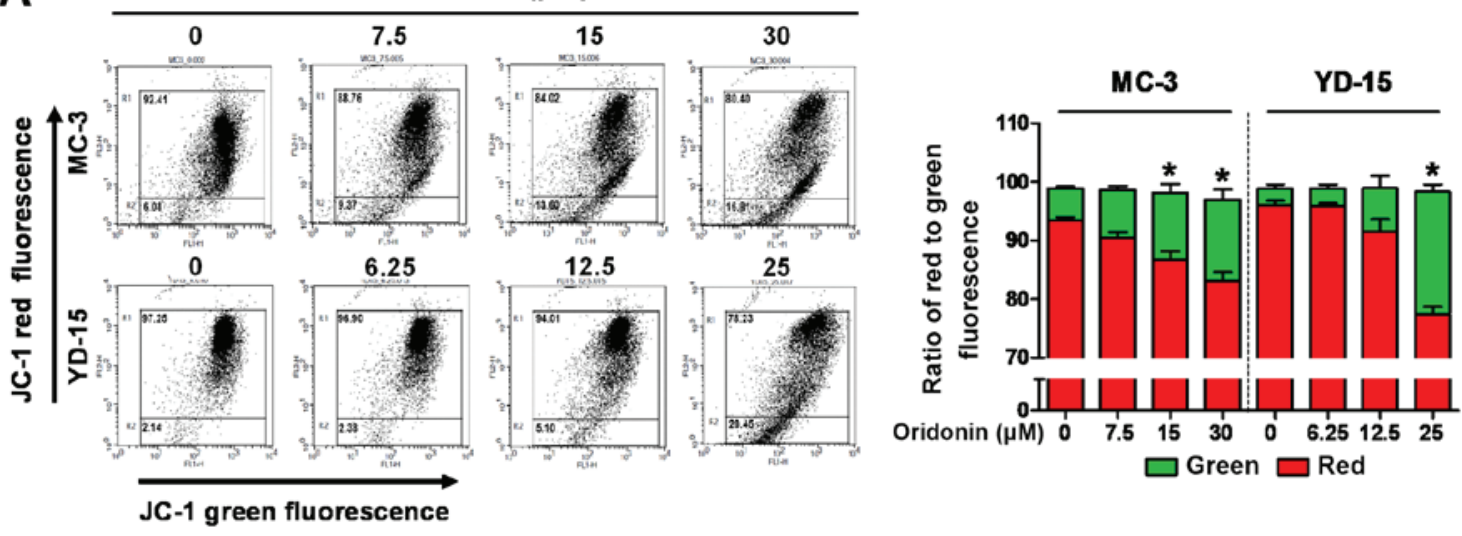

B

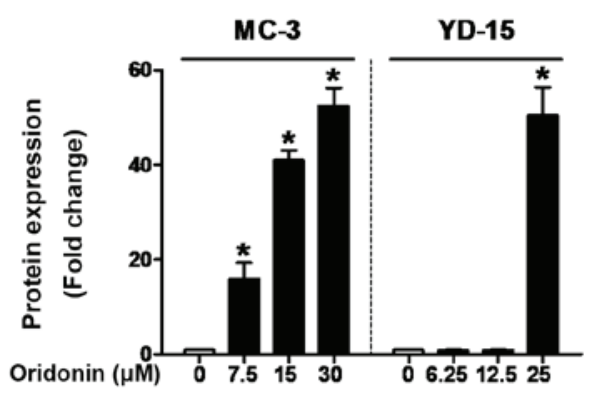

C
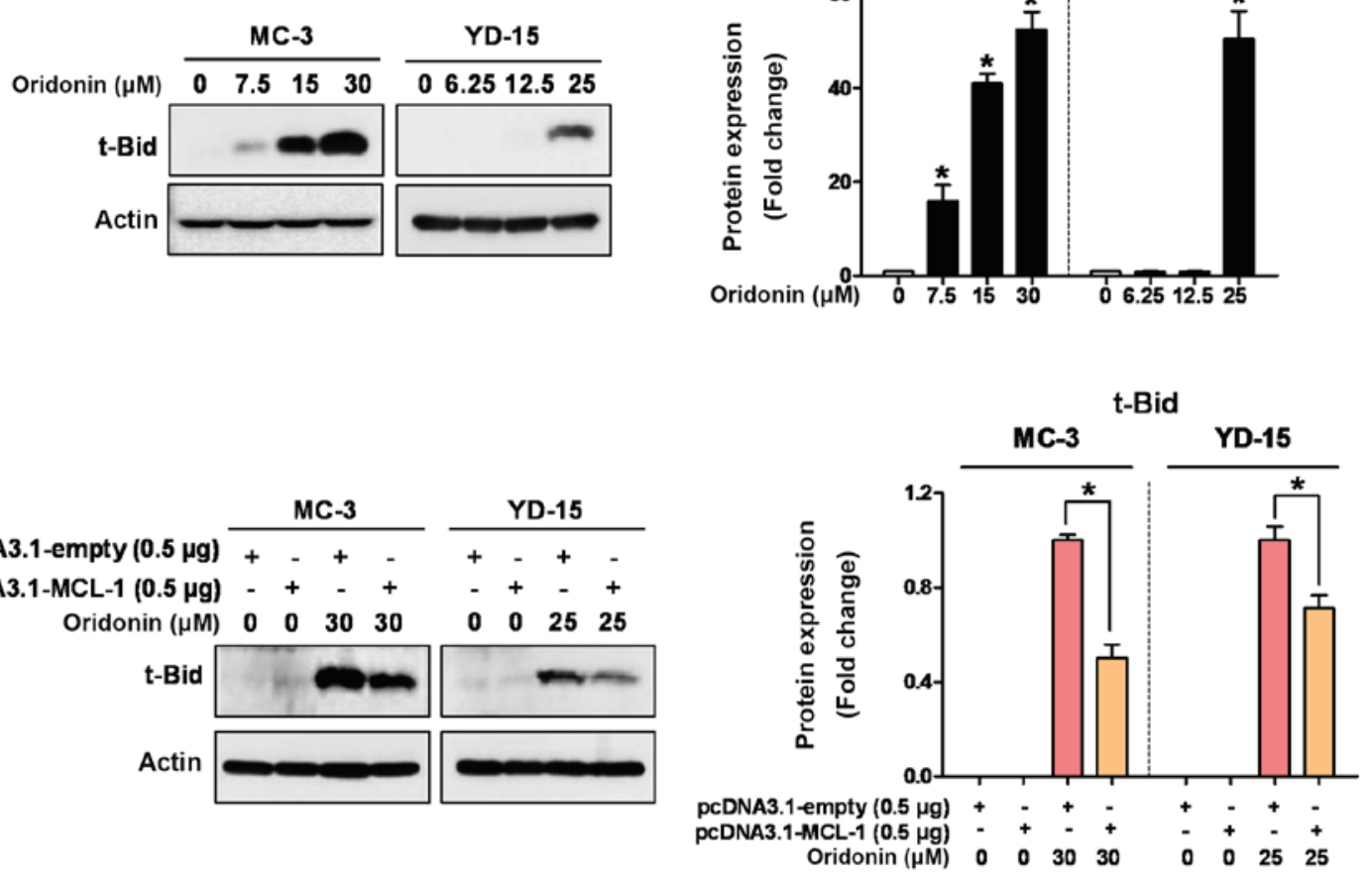

Figure 5. Loss of MOMP and t-Bid expression in oridonin-treated MEC cell lines. (A) MOMP was determined using a JC-1 assay. (B) The expression level of $\mathrm{t}$-Bid protein was determined by western blot analysis. (C) Cells were transiently transfected with $0.5 \mu \mathrm{g}$ of empty pcDNA3.1 or pcDNA3.1-MCL-1 and treated with oridonin for $48 \mathrm{~h}$. Expression level of t-Bid was determined by western blot analysis. Graph shows the means \pm SD of 3 independent experiments. " $\mathrm{P}<0.05$, significant difference compared with the control group. MEC, mucoepidermoid carcinoma.

determine whether oridonin induces apoptosis through mitochondrial dysfunction. Oridonin exerted a significant decrease in red fluorescence compared to the vehicle control, confirming that the loss of $\Delta \Psi \mathrm{m}$ was induced in both cell lines (Fig. 5A). Subsequently, to further examine the mitochondrial-dependent pathway involved in oridonin-mediated apoptosis, the expression levels of pro-apoptotic proteins were analyzed. As shown in Fig. 5B, the expression of t-Bid was markedly increased by oridonin in a concentration-dependent manner, whereas the levels of other pro-apoptotic proteins, such as Bak, Bax and Bim were not commonly affected in both cell lines (Fig. S1). To ascertain the involvement of MCL-1 in t-Bid expression during oridonin-induced apoptosis, an MCL-1 expression vector was used. As was expected, the ectopic expression of MCL-1 protein significantly decreased the expression of $\mathrm{t}-\mathrm{Bid}$ in the oridonin-treated cells (Fig. 5C). These results suggest that $\mathrm{t}-\mathrm{Bid}$ may be an essential downstream molecule of MCL-1 during the oridonin-induced apoptosis of MEC cell lines.

\section{Discussion}

MCL-1, a pro-survival member of the Bcl-2 family, has been shown to be highly expressed in human malignancies, which has led to increased attention in oral cancer, including other solid tumors $(27,28)$. Notably, human oral cancer cells have been shown to exhibit an elevated expression of MCL-1 protein compared to their normal counterparts, human oral keratinocytes, while Bcl-2 exhibits a negligible expression in most cells $(28,29)$. Furthermore, it has been reported that MCL-1 overexpression is resistant to Bcl-2 family inhibitors, such as paclitaxel, vincristine and gemcitabine, which are well-known anticancer therapeutic agents $(30,31)$. Thus, the 
downregulation of MCL-1 may be a key step in promoting the apoptosis of cancer cells and the use of natural compounds to modulate the expression or function of MCL-1 protein has recently been viewed as a promising alternative for the development of preventive and therapeutic regimens $(32,33)$. Previous studies by the authors have found that natural products, such as mithramycin A, fisetin and fucoidan inhibit the expression of MCL-1 protein, leading to the apoptosis of human oral cancer cells $(29,34,35)$. The authors have also previously reported that oridonin induces apoptosis by increasing the expression of $\gamma \mathrm{H} 2 \mathrm{AX}$ in response to DNA damage (18). Despite several studies being published the apoptotic effects of oridonin, its mode of action in downregulating MCL-1 has not yet been fully elucidated $(36,37)$. In the present study, for the first time, to the best of our knowledge, it was found that oridonin induced apoptosis through the downregulation of MCL-1 in human MEC cell lines, independent of transcriptional regulation (Figs. 2 and 3). It was also demonstrated that the overexpression of MCL-1 effectively abrogated oridonin-induced apoptosis (Fig. 4). In present study, these results support the notion that MCL-1 is an important survival factor and that its downregulation is a potential therapeutic strategy for MEC.

In response to apoptotic stimuli, the $\mathrm{BH} 3$-only proteins are upregulated to allow the activation of Bax and Bak for oligomerization in the outer-mitochondrial membrane known as MOMP, leading to the release of cytochrome $c$ and other apoptosis-inducing factors (38). This indicates that the impairment of MOMP by the Bcl-2 family is the cornerstone of intrinsic apoptotic pathways. In the present study, it was found that oridonin treatment significantly induced the loss of MOMP through the upregulation of $\mathrm{t}$-Bid expression in a concentration-dependent manner, accompanied by marked apoptotic cell death. Liu et al obtained similar results, demonstrating that the gradual increase in the MOMP destruction rate by oridonin in the HPB-ALL cell line occurred through the upregulation of t-Bid (39). Thus, these findings emphasize that oridonin-induced apoptosis is closely related to or is dependent on the loss of MOMP through the MCL-1/t-Bid signaling axis in human MEC cell lines.

In conclusion, the present study demonstrated for the first time, to the best of our knowledge, that the downregulation of MCL-1 by oridonin promotes apoptosis through the loss of MOMP and that t-Bid is a critical downstream target of MCL-1 in the oridonin-induced apoptosis of human MEC cell lines. Taken together, MCL-1 may prove to be a valuable molecular target for oridonin-mediated anticancer activity. Oridonin is thus recommended as a naturally derived chemotherapeutic drug candidate for the treatment of MEC.

\section{Acknowledgements}

Not applicable.

\section{Funding}

The present study was supported by the Basic Science Research Program through the National Research Foundation of Korea (NRF) funded by the Ministry of Science, ICT, and Future Planning (grant nos. 2017R1D1A1B03029317, 2018R1D1A1B07043080 and 2019R1A2C10858 96).

\section{Availability of data and materials}

All data generated or analyzed during this study are included in the current published article.

\section{Authors' contributions}

JMH designed the study, analyzed and interpreted the results, and drafted the manuscript. $\mathrm{KOH}$ contributed to the manuscript preparation, the study design and statistical analysis. IHY managed the cellular samples and was involved in data acquisition. CHA contributed to the quality control of the data. BJ and WL performed the statistical analysis and wrote the methods section. JAS performed the statistical analysis and was involved in data interpretation. KAK and YCJ contributed to writing parts of the Material and methods section and conducted data analysis. KAK contributed to the interpretation of the revised data (Figs. 4 and 5) and wrote the revised manuscript. SDC and SDH interpreted the results and supervised the study and contributed to manuscript reviewing and editing, and critically revised the manuscript. All authors were involved in the final version of the manuscript.

\section{Ethics approval and consent to participate}

Not applicable.

\section{Patient consent for publication}

Not applicable.

\section{Competing interests}

The authors declare that they have no competing interests.

\section{References}

1. Venkata $V$ and Irulandy $P$ : The frequency and distribution pattern of minor salivary gland tumors in a government dental teaching hospital, Chennai, India. Oral Surg Oral Med Oral Pathol Oral Radiol Endod 111: e32-e39, 2011.

2. Schwarz S, Stiegler C, Müller M, Ettl T, Brockhoff G, Zenk J and Agaimy A: Salivary gland mucoepidermoid carcinoma is a clinically, morphologically and genetically heterogeneous entity: A clinicopathological study of 40 cases with emphasis on grading, histological variants and presence of the $t(11 ; 19)$ translocation. Histopathology 58: 557-570, 2011.

3. Birkeland AC, Foltin SK, Michmerhuizen NL, Hoesli RC, Rosko AJ, Byrd S, Yanik M, Nor JE, Bradford CR, Prince ME, et al: Correlation of Crtc1/3-Maml2 fusion status, grade and survival in mucoepidermoid carcinoma. Oral Oncol 68: 5-8, 2017.

4. Rapidis AD, Givalos N, Gakiopoulou H, Stavrianos SD, Faratzis G, Lagogiannis GA, Katsilieris I and Patsouris E: Mucoepidermoid carcinoma of the salivary glands. Review of the literature and clinicopathological analysis of 18 patients. Oral Oncol 43: 130-136, 2007.

5. Green B, Rahimi S and Brennan PA: Salivary gland malignancies-an update on current management for oral healthcare practitioners. Oral Dis 22: 735-739, 2016.

6. Chan HK and Ismail S: Side effects of chemotherapy among cancer patients in a Malaysian General Hospital: Experiences, perceptions and informational needs from clinical pharmacists. Asian Pac J Cancer Prev 15: 5305-5309, 2014.

7. Thomas LW, Lam C and Edwards SW: Mcl-1; the molecular regulation of protein function. FEBS Lett 584: 2981-2989, 2010. 
8. Senichkin VV, Streletskaia AY, Zhivotovsky B and Kopeina GS Molecular comprehension of Mcl-1: From gene structure to cancer therapy. Trends Cell Biol 29: 549-562, 2019.

9. Opferman JT, Letai A, Beard C, Sorcinelli MD, Ong CC and Korsmeyer SJ: Development and maintenance of B and T lymphocytes requires antiapoptotic MCL-1. Nature 426: 671-676, 2003.

10. Sieghart W, Losert D, Strommer S, Cejka D, Schmid K Rasoul-Rockenschaub S, Bodingbauer M, Crevenna R, Monia BP, Peck-Radosavljevic M and Wacheck V: Mcl-1 overexpression in hepatocellular carcinoma: A potential target for antisense therapy. J Hepatol 44: 151-157, 2006.

11. Campbell KJ, Dhayade S, Ferrari N, Sims AH, Johnson E, Mason SM, Dickson A, Ryan KM, Kalna G, Edwards J, et al: MCL-1 is a prognostic indicator and drug target in breast cancer. Cell Death Dis 9: 19,2018.

12. Lin J, Fu D, Dai Y, Lin J and Xu T: Mcl-1 inhibitor suppresses tumor growth of esophageal squamous cell carcinoma in a mouse model. Oncotarget 8: 114457-114462, 2017.

13. Gény C, Rivière G, Bignon J, Birlirakis N, Guittet E, Awang K, Litaudon M, Roussi F and Dumontet V: Anacardic acids from knema hookeriana as modulators of Bcl-xL/Bak and Mcl-1/Bid interactions. J Nat Prod 79: 838-844, 2016.

14. Choi ES, Kim JS, Kwon KH, Kim HS, Cho NP and Cho SD: Methanol extract of Sanguisorba officinalis L. with cytotoxic activity against PC3 human prostate cancer cells. Mol Med Rep 6: 670-674, 2012.

15. Clohessy JG, Zhuang J, de Boer J, Gil-Gómez G and Brady HJ: Mcl-1 interacts with truncated Bid and inhibits its induction of cytochrome c release and its role in receptor-mediated apoptosis. J Biol Chem 281: 5750-5759, 2006.

16. Bolaños JP, Moro MA, Lizasoain I and Almeida A: Mitochondria and reactive oxygen and nitrogen species in neurological disorders and stroke: Therapeutic implications. Adv Drug Deliv Rev 61: 1299-1315, 2009.

17. Wang S, Zhong Z, Wan J, Tan W, Wu G, Chen M and Wang Y: Oridonin induces apoptosis, inhibits migration and invasion on highly-metastatic human breast cancer cells. Am J Chin Med 41: 177-196, 2013.

18. Yang IH, Shin JA, Lee KE, Kim J, Cho NP and Cho SD: Oridonin induces apoptosis in human oral cancer cells via phosphorylation of histone H2AX. Eur J Oral Sci 125: 438-443, 2017.

19. Jin S, Shen JN, Wang J, Huang G and Zhou JG: Oridonin induced apoptosis through Akt and MAPKs signaling pathways in human osteosarcoma cells. Cancer Biol Ther 6: 261-268, 2007.

20. Cheng Y, Qiu F, Ye YC, Tashiro S, Onodera S and Ikejima T: Oridonin induces $\mathrm{G} 2 / \mathrm{M}$ arrest and apoptosis via activating ERK-p53 apoptotic pathway and inhibiting PTK-Ras-Raf-JNK survival pathway in murine fibrosarcoma L929 cells. Arch Biochem Biophys 490: 70-75, 2009

21. Hu HZ, Yang YB, Xu XD, Shen HW, Shu YM, Ren Z, Li XM, Shen HM and Zeng HT: Oridonin induces apoptosis via PI3K/Akt pathway in cervical carcinoma HeLa cell line. Acta Pharmacol Sin 28: 1819-1826, 2007.

22. Lu J, Chen X, Qu S, Yao B, Xu Y, Wu J, Jin Y and Ma C: Oridonin induces $\mathrm{G}_{2} / \mathrm{M}$ cell cycle arrest and apoptosis via the PI3K/Akt signaling pathway in hormone-independent prostate cancer cells. Oncol Lett 13: 2838-2846, 2017.

23. Wang H, Zhu L, Feng X, Zhang H, Luo Q and Chen F: Oridonin induces $\mathrm{G} 2 / \mathrm{M}$ cell cycle arrest and apoptosis in human oral squamous cell carcinoma. Eur J Pharmacol 815: 282-289, 2017.
24. Li S, Shi D, Zhang L, Yang F and Cheng G: Oridonin enhances the radiosensitivity of lung cancer cells by upregulating Bax and downregulating Bcl-2. Exp Ther Med 16: 4859-4864, 2018.

25. Livak KJ and Schmittgen TD: Analysis of relative gene expression data using real-time quantitative PCR and the 2(-Delta Delta C(T)) method. Methods 25: 402-408, 2001.

26. Tait SW and Green DR: Mitochondria and cell death: Outer membrane permeabilization and beyond. Nat Rev Mol Cell Biol 11: 621-632, 2010.

27. Akgul C: Mcl-1 is a potential therapeutic target in multiple types of cancer. Cell Mol Life Sci 66: 1326-1336, 2009.

28. Maji S, Samal SK, Pattanaik L, Panda S, Quinn BA, Das SK, Sarkar D, Pellecchia M, Fisher PB and Dash R: Mcl-1 is an important therapeutic target for oral squamous cell carcinomas. Oncotarget 6: 16623-16637, 2015.

29. Shin JA, Jung JY, Ryu MH, Safe S and Cho SD: Mithramycin A inhibits myeloid cell leukemia-1 to induce apoptosis in oral squamous cell carcinomas and tumor xenograft through activation of Bax and oligomerization. Mol Pharmacol 83: 33-41, 2013.

30. Wertz IE, Kusam S, Lam C, Okamoto T, Sandoval W, Anderson DJ, Helgason E, Ernst JA, Eby M, Liu J, et al: Sensitivity to antitubulin chemotherapeutics is regulated by MCL1 and FBW7. Nature 471: 110-114, 2011.

31. Wei SH, Dong K, Lin F, Wang X, Li B, Shen JJ, Zhang Q, Wang R and Zhang HZ: Inducing apoptosis and enhancing chemosensitivity to gemcitabine via RNA interference targeting Mcl-1 gene in pancreatic carcinoma cell. Cancer Chemother Pharmacol 62: 1055-1064, 2008

32. Muller F, Cerella C, Radogna F, Dicato M and Diederich M: Effects of natural products on Mcl-1 expression and function. Curr Med Chem 22: 3447-3461, 2015.

33. Hanahan D and Weinberg RA: Hallmarks of cancer: The next generation. Cell 144: 646-674, 2011.

34. Won DH, Chung SH, Shin JA, Hong KO, Yang IH, Yun JW and Cho SD: Induction of sestrin 2 is associated with fisetin-mediated apoptosis in human head and neck cancer cell lines. J Clin Biochem Nutr 64: 97-105, 2019.

35. Lee HE, Choi ES, Shin JA, Lee SO, Park KS, Cho NP and Cho SD: Fucoidan induces caspase-dependent apoptosis in MC3 human mucoepidermoid carcinoma cells. Exp Ther Med 7: 228-232, 2014.

36. Zhang HP, Li GQ, Guo WZ, Chen GH, Tang HW, Yan B, Li J, Zhang JK, Wen $\mathrm{PH}$, Wang $\mathrm{ZH}$, et al: Oridonin synergistically enhances JQ1-triggered apoptosis in hepatocellular cancer cells through mitochondrial pathway. Oncotarget 8: 106833-106843, 2017.

37. Ikezoe T, Yang Y, Bandobashi K, Saito T, Takemoto S, Machida H, Togitani K, Koeffler HP and Taguchi H: Oridonin, a diterpenoid purified from Rabdosia rubescens, inhibits the proliferation of cells from lymphoid malignancies in association with blockade of the NF-kappa B signal pathways. Mol Cancer Ther 4: 578-586, 2005.

38. Roy MJ, Vom A, Czabotar PE and Lessene G: Cell death and the mitochondria: Therapeutic targeting of the BCL-2 family-driven pathway. Br J Pharmacol 171: 1973-1987, 2014

39. Liu JJ, Huang RW, Lin DJ, Wu XY, Peng J, Pan XL, Lin Q, Hou M, Zhang MH and Chen F: Antiproliferation effects of oridonin on HPB-ALL cells and its mechanisms of action. Am J Hematol 81: 86-94, 2006. 